\section{Clinital Plotes:}

MEDICAL, SURGICAL, OBSTETRICAL, AND THERAPEUTICAL.

\section{UROTROPIN IN THE PYURIA OF TABES DORSALIS.}

BY WALKeR Overend, M.A., M.D. OXON., B.Sc. LOND., LATE SENIOR PHYSICIAN TO THE TOTTENHAM HOSPITAL AND RADCLIFFE TRAVELLING FELLOW.

THE following case presents some points of interest. The patient, who was 36 years of age, exhibited the classical symptoms and signs of locomotor ataxia-occasional lightning pains, loss of knee-jerk, muscular incoördination, and vesical troubles. About April, 1899, he first noticed that the bed was wet of a morning, and soon afterwards the urine began to dribble during the day. It gradually commenced to run faster, until after a few months he never passed it at all in a natural manner but suffered from complete incontinence. He was compelled to wear an indiarubber urinal constantly. In the spring of 1900 he resigned his situation and went to live at the seaside. In March, 1901, he consulted me, but not for treatment of the bladder condition, inasmuch as he considered that to be hopeless and incurable. He had, as an out-patient, attended one of the special London hospitals for several years. I persuaded him to take a mixture containing ergot for a time but it proved useless. I then recommended eight grains of urotropin daily but he did not persevere with it. In September, 1901, he contracted influenza but recovered after a few days. The urine was ammoniacal and contained much pus. He was then passing nearly two pints into the urinal during the night and sleep was restless and disturbed. The ignominy of the wretched condition preyed upon his mind and he was morbid, depressed, and hypochondriacal. The vesical weakness in consequence became aggravated. I emphasised the necessity of resuming the urotropin and of taking it regularly for some months, and, irrigation being declined, assured him that the urotropin would greatly benefit him. In February, 1902, he stated that eight grains of urotropin had been taken daily for five months and that he felt much better. There had been no sign of hæmorrhage. The urinal was now practically dry at bedtime; he passed on his own initiative about two pints without pain during the day and the urinal in the early morning contained less than three-quarters of a pint. Moreover, he slept well and was looking out for some employment. One day in January he experienced-for the first time in two years-the desire to micturate. Since then he has learnt to ride a bicycle and he makes use of the machine in his new situation. The urine is free from pus and albumin and has an acid reaction which it retains even after standing for 24 hours. The urinal contains not more than half a pint of urine in the morning and only a few drops at bedtime. I suggested that he should continue the use of the urotropin until the dribbling ceased.

The regular administration of other vesical disinfectants such as salol might have led to equally good results and it seems reasonable to attribute a share of the improvement at least to the asepsis produced by the diurnal exhibition of the drug. The presence of a normal urine within the bladder with the absence of pyuria gave the sphincter an opportunity to recover its tone and the detrusor vesicæ its power. The restoration of physical tone and general mental equilibrium - a result of much exercise in the open air-no doubt assisted and favourably reacted upon the beneficial action of the urotropin. The addition of from one-fiftieth to one-hundredth of a grain of strychnine to the urotropin would probably facilitate the effect. The same combination may be suggested for the chronic vesical catarrh and pyuria of enlarged prostate and of diabetes as well as that of hemiplegia and senile debility.

Clacton-on-sea.

\section{CASES OF STOKES-ADATIS DISEASE (?).}

By IsaaC Crawford, L.R.C.P. \& S. Edin., L.F.P.S. Glasg.

EIGHT years ago I attended a woman during an attack of pneumonia. She was above medium height, married, of sallow complexion, and very thin. There was nothing about the pneumonia to call for special comment, save that resolution was somewhat delayed.

At the end of the first week of the illness, having been hurriedly summoned, as she was supposed to be dying, I found her pulseless at the wrists and quite unconscious while her breathing was imperceptible. There was a faint, slow flicker to be detected with difficulty in the region of the cardiac apex. Injections of strychnine and digitalin were employed and heat was applied to the extremities and præcordia. She slowly revived, the heart-beats gaining in strength and rhythm until the heart behaved in its customary manner. On inquiry her friends said that the oncoming of unconsciousness was gradual. She had five similar attacks, there being an interval of several days prior to the last which proved fatal. Digitalis was given and curiously enough it was stopped about a couple of days before the last attack. Whether that contributed to the fatal result it is hard to say. In the intervals the heart was normal, no murmur or irregularity being observable. There was no history of any previous similar attacks.

About the same time I attended another patient whose heart behaved in a manner somewhat similar to the above. She was a primipara whom 1 delivered with instruments under chloroform. There was some hæmorrhage but not enough to be dignified by the name of post-partum hæmor rhage. She then for no obvious cause passed gradually into a state of unconsciousness. Her pulse became slower and weaker and finally could not be felt at the wrists; her breathing could not be perceived; her cheeks became white; her limbs grew cold; and the fingers could not detect any sign of life at the cardiac apex. She lay in bed as motionless as if she were carved out of marble. Similar steps towards restoration were taken as in the previous case but I had to leave her still unconscious. Early in the morning I called again at the house and to my great relief I found her in excellent spirits and condition. She had recovered shortly after my departure.

There are references to the above condition in some of the text-books but nothing clear or explicit. I am unable to offer any explanation of the phenomena now described.

Tredegar, Mon.

\section{d attlitror}

\section{HOSPITAL PRACTICE, BRITISH AND FOREIGN.}

Nulla autem est alia pro certo noseendi via, nisi quamplurimas et morborum et dissectionum historias, tum aliorum tum propria collectas habere, ot inter se comparare.-MorgaGNI De Sed. et Caus. Morb., lib. iv., Procmium.

\section{ROMFORD UNION INFIRMARY.}

A FATAL CASE OF TETANY IN ASSOCIATION WITH DILATATION OF THE SMALL INTESTINE.

(Under the care of Dr. Dudley G. GReEnfield.)

A MARRIED woman, aged 33 years, was admitted into Romford Union Infirmary under the care of Dr. Greenfield on August 29th. She had had three children, the youngest of whom was nine months old. About 12 days before admission she had been seized with vomiting and had been steadily getting worse. She had previously had no serious illnesses but for some weeks she had been badly fed and cared for. The bowels had been relieved twice during this time on the administration of an enema. On admission the patient had a very worn appearance and complained of lack of sleep owing to the vomiting. She had no acute pain at any time. The vomiting was distressing and very frequent. The vomit was distinctly fæcal in odour and in appearance it was very like a characteristic typhoid stool. The abdomen was considerably distended and tympanitic on percussion, the normal areas of dulness being preserved. It moved fairly well on respiration, no pain was caused on palpation, and no tumour could be felt. The abdominal wall was not in the least rigid and no peristalsis was visible. The bowels had been relieved two days previously after an enema and the patient's gereral condition was fairly good. A soap enema was administered and a 
very large evacuation of clay-coloured fæces resulted and about half an hour afterwards the bowels again acted freely. The patient expressed great relief and said that she "felt a different woman." The distension of the abdomen was considerably less. She was given albumin water only by the mouth and plain water when thirsty. Five grains of calomel were given but she vomited shortly after. In the evening she was more comfortable, the vomiting was less, and the bowels were moved slightly after an enema. The tongue was moist, the pulse was good, and the abdomen was only slightly distended.

On August 30th the patient had passed a good night and felt much better as she had not slept for several days. The vomiting was only occasional. The vomit had lost its fæcal odour and was only bilious. There was a good result from an enema, the frees being yellowish and loose and no longer clay-coloured. Another five grains of calomel were given without result. The abdomen was said by the patient to be of about the natural size. Albumin water was still the only food given and she had also ten grains of salol every four hours. In the evening she had two typical attacks of tetany, involving the hands, the feet, and the face and lasting about half an hour on each occasion, giving the patient much alarm. The marked abatement of symptoms, the disappearance of the fæcal odour from the vomit, the four actions of the bowels, and the approach to normal of the last motion all seemed to negative a diagnosis of intestinal obstruction other than that due to impacted fæces. The possibility of a gastro-intestinal fistula was considered and some disease of the pancreas was suggested by the whitish frces but nothing could be felt on deep palpation of the abdomen. On the 3lst the vomiting had ceased entirely and the bowels acted freely after an enema. The pulse was good, about 90, and the temperature was slightly subnormal. She had another attack of tetany lasting about 40 minutes. On Sept. 1st the patient had slept well after an injection of morphia given for the attack of tetany on the previous evening. There was no return of the vomiting and she took plenty of albumin water and fluid by the mouth. She was also given nutrient enemata of starch, eggs, salt, and milk to eight ounces every six hours, but the bulk had to be reduced owing to a bad tear of the perineum (not recent) and difficulty in retention. The bowels acted when the rectum was washed out with saline solution preparatory to the administration of the nutrient enema. The only adverse symptom at this time was the subnormal temperature, but the pulse was good and the extremities did not feel cold. On the 2 nd the bowels were opened after the wash-out of the rectum in the morning. The albumin water was well retained as were also the nutrient enemata. In the evening she became very cold and collapsed, but improved again when some stimulant was administered. On the 3rd the patient was better again. The food given by the mouth was increased and the nutrient enemata were administered only twice daily. She took one and a half pints of peptonised milk, two ounces of pounded beef, some essence of beef, beside one pint of albumin water and retained it all. On the 4th her appearance had improved considerably, her face being much fuller. The pulse was good but the temperature was still slightly subnormal. Slight peristalsis was visible in the morning and in the afternoon the vomiting returned. On the 5th the patient had vomited frequently in the night, small quantities of bilious material being brought up. The bowels were moved several times quite naturally; the fæces were loose but normal in appearance, no blood or mucus being present Peristalsis was again seen in the morning and her friends were advised that an operation would probably be required. In the afternoon, however, she became rapidly worse and died unexpectedly.

Necropsy. A partial examination was permitted. On openirg the abdomen some very distended coils of small intestine lay in front, matted together by some tough adhesions. These proved to be the upper part of the jejunum, the lower half of the jejunum and the ileum being empty and contracted. The junction of the distended and contracted portions was matted firmly down behind, close to the root of the m-sentery. A finger passed down from above easily went thrugh the point of apparent obstruction and that before the positions of the parts were much disturbed. On unravelling the coils no cause of obstruction could be determined. There was no fibrous stricture and no evidence of dragging or strangulation could be demonstrated. There was very slight capillary injection of the lowest end of the distended portion but there was no extravasation of blood, no lymph, or any sign of recent peritonitis. The pancreas was apparently healthy and the peritoneum showed no hæmorrhages or fatty masses. The stomach was not dilated and was free from any sign of ulceration. The rest of the abdominal viscera and the heart were quite normal in appearance.

Remarks. - From the post-mortem examination it is clear that the primary trouble was acute dilatation of the upper part of the swall intestine. No obstruction could be discovered although the patient had old peritoneal adhesions and seeing that the bowels were opened well on each day that she was in the infirmary (eight days in all) and that on the last two days the bowels were opened naturally several times, no obstruction was probably present. Was this then a paralytic distension? The occurrence of tetany was very interesting in a case of this sort. It was fortunate that no operative interference was attempted as the utmost that could have been done was to have relieved the distended bowel and any attempt to arrive at the point of apparent obstruction would have been useless and im. practicable owing to the dense bands of fibrous tissue. The post-mortem examination proved that the suspicion of pancreatic disease as a cause of these conflicting symptoms was unfounded.

The case came under my care while doing the work of Mr. J. A. Fraser of Romford and $I$ am indebted to him for permission to publish this account.

\section{HERTFORD GENERAL INFIRMARY.}

A CASE OF SUPPURATING HYDATID; INFECTIVE ENDOCARDITIS ; ANEURYSM OF THE PERONEAL ARTERY.

For the notes of the case we are indebted to Dr. Gordon Moir, house surgeon.

The patient, a lad, aged 19 years, was admitted to the Hertford General Intirmary on June 18th with the following history. His occupation was gardening on an estate in Hertfordshire, where he had lived all his life. His family history was very good, but one sister had recently died from phthisis. He had always been perfectly healthy except for typhoid fever which he had had nine years previously. $\mathrm{He}$ had never had any venereal disease and there was none in the family. In the beginning of May, 1903, he had a "feverish attack" and was laid up for a day or so, which he soon got over and resumed work. At the end of May whilst going to his work he was seized with sudden pain in the left leg and had to return home; he could hardly walk, the pain was so severe. He returned to work the next day and remained at it for three days, when the pain in his leg became so acute that he stayed at home and kept in bed with the foot raised. It was noticed at this time that there was a swelling in his leg; pulsation was not noticed till a week after its first appearance, when it had become slightly larger. The leg was swollen and painful.

On admission it was noted that the patient was a strong, healthy-looking lad, rather pale about the lips, and his voice was rather quavering. On the left leg, about two and a half inches below the head of the fibula on the postero-external surface, there was a hard, tense swelling of about the size of a fowl's egg. The skin was not adherent or reddened; it was slightly painful. The swelling was deeply situated, not moveable, and elongated. There was a distinct expansile pulsation. On compressing the popliteal artery pulsation was lessened, but there was no decrease in size; on releasing the artery the swelling regained its maximum pulsation in three or four beats. There was loss of pulsation in both anterior and posterior tibial arteries in the foot; the left ankle was somewhat swollen. The left leg measured $11 \frac{1}{2}$ inches and the right $10 \frac{1}{2}$ inches. The knee-joint was normal and there was no pain on flexion. There were no enlarged glands on the left side, but there were a few in the right groin. On examining his heart the impulse was in the fifth space just internal to the nipple line. Dulness extended to the second costal cartilage and to the right edge of the sternum. There were a loud presystolic bruit and a systolic murmur traceable to the angle of the scapula. On impulse there were an accentuated pulmonary second sound, a loud diastolic bruit in the aortic region, and a faint systolic bruit. The liver was not palpable; dulness did not extend below the margin of the ribs. The spleen was distinctly enlarged, coming down three and a half inches on 